\title{
Estreptococo B: uma análise da prevalência, da efetividade do rastreamento e dos fatores associados a sua má performance
}

\author{
Acadêmicos: Anna Carolina Cipparrone Scorzelli, Amanda Macdarino Alves, Ariane Encarnação \\ Ferreira
}

Orientadores: Tânia Di Giacano do Lago, Lilian de Paiva Rodrigues Hiu

Introdução: O Streptococcus agalactiae (EBG) é uma bactéria da microbiota humana, cuja colonização vaginal entre mulheres grávidas varia entre 10-30\%. Sua transmissão vertical está relacionada a meningite, pneumonia e septicemia no neonato. Como principal estratégia para a prevenção de morbidades relacionadas ao EBG, é preconizada a pesquisa da colonização em gestantes entre 35 e 37 semanas por meio de cultura de secreção com swab ano-vaginal. Esta ação preventiva tem eficácia estimada em torno de 25-30\%, reduzindo a mortalidade neonatal em 10\%, e é implementada na cidade de São Paulo pela Secretaria Municipal de Saúde desde 2007.

Objetivo: O presente estudo teve como objetivo identificar a prevalência do EBG, a adequação do seu rastreamento e os principais fatores associados a um possível desfecho negativo.

Metodologia: Estudo transversal realizado com 840 parturientes admitidas em uma maternidade pública de São Paulo entre 2012 e 2013. A coleta de dados foi feita por meio de entrevistas às puérperas e consulta de prontuários. Foram excluídas aquelas que tiveram perda fetal ou se recusaram a participar. A amostra permite estimar taxa de adequação de $50 \%$ com intervalo de confiança de $95 \%$ e erro amostral de $5 \%$. O processamento e análise dos dados foram realizados no software SPSS versão 17.

Resultados: $37,3 \%$ das entrevistadas eram primigestas, 97\% realizaram pré-natal, e 77,5\% destas realizaram mínimo de 6 consultas. O parto a termo ocorreu em $81,7 \%$ dos casos, principalmente por via vaginal. A coleta do swab foi realizada por $56,1 \%$ das pacientes, e destas $63,6 \%$ o fizeram no tempo adequado. Os resultados da cultura do EBG foram positivos em $19,7 \%$ dos casos, negativos em $62,8 \%$ e desconhecidos em 17,4\%. A prevalência do EBG em relação à amostra total foi de $11,1 \%$ e entre aquelas com resultado conhecido foi de $22,5 \%$. O resultado estava disponível no momento do parto para $81,3 \%$ das mulheres que realizaram o exame, ou 46,3\% em relação à amostra total. A efetividade do rastreamento foi de 28,9\%. Os fatores que se associaram à má performance no rastreamento do EBG foram: idade inferior a 25 anos $(p=0,02)$, cor preta ou amarela $(p=0,00)$, nacionalidade $(p=0,01)$, menos de 6 consultas de pré natal $(p=0,00)$ e o local de realização $(p=0,024)$. Não ter o ensino médio completo $(p=0,091)$ e não ser primigesta $(p=0,0125)$ se associaram mais frequentemente a falta do resultado da cultura, entretanto não foram estatisticamente significantes.

Discussão: No presente estudo, a taxa de colonização materna pelo EGB foi ao encontro dos valores mais altos observados nos estudos nacionais. A freqüência do rastreamento foi muito baixa em nossa amostra, e dentre os fatores já citados que contribuíram para essa má performance, estes podem ser explicados pela barreira lingüística que atinge as mulheres de outras nacionalidades e que dificulta a realização das consultas de pré natal, em especial as chinesas e mulheres negras provenientes da África e da América Central; a má assistência ao pré Natal na maior parte das Unidades de Saúde de São Paulo; e um menor senso de responsabilidade, em geral, em gestantes muito jovens. 